\title{
Influences of Cation and Anion Substitutions on Oxidative Coupling of Methane over Hydroxyapatite Catalysts
}

\author{
Su Cheun $\mathrm{Oh}^{1}$, Yiqing $\mathrm{Wu}^{1}$, Dat T. Tran ${ }^{2}$, Ivan C. Lee ${ }^{2}$, Yu Lei ${ }^{3}$ and Dongxia Liu ${ }^{1 *}$
}

1. Department of Chemical and Biomolecular Engineering, University of Maryland, College Park, MD, 20742

2. U.S. Army Research Laboratory, RDRL-SED-E, 2800 Powder Mill Road, Adelphi, MD, 20783, USA

3. Chemical and Materials Engineering, the University of Alabama in Huntsville, 301 Sparkman Drive, Huntsville, AL 35899

*Corresponding author:

Prof. Dongxia Liu

Email: liud@umd.edu

Phone: (+1) 301-405-3522

Fax: (+1) 301-405-0523 
Abstract: Lead substituted hydroxyapatite (Pb-HAP) has been an active catalyst for oxidative coupling of methane $(\mathrm{OCM})$ reactions. $\mathrm{CO}_{3}{ }^{2-}$ substituted $\mathrm{HAP}\left(\mathrm{HAP}-\mathrm{CO}_{3}\right)$ has showed enhanced oxide ion conductivity than bare HAP in high temperature solid oxide fuel cells. Substitutions for both cations and anions in $\mathrm{HAP}$ structure $\left(\mathrm{Pb}-\mathrm{HAP}-\mathrm{CO}_{3}\right)$ are promising to integrate the catalytic property of $\mathrm{Pb}-\mathrm{HAP}$ and oxide ion conductive property of $\mathrm{HAP}-\mathrm{CO}_{3}$ into one apatite-based ceramic material that can be manufactured into membrane reactors for possessing $\mathrm{CH}_{4}$ activation and $\mathrm{O}_{2}$ permeation capabilities for efficient OCM reactions. In this work, the effects of substitutions for both cation $\left(\mathrm{Pb}^{2+}\right)$ and anion $\left(\mathrm{CO}_{3}{ }^{2-}\right)$ in $\mathrm{HAP}$ structure on OCM reactions were studied. The composition and physicochemical properties of HAP catalysts were changed by the cation and anion substitutions, respectively, and as consequences, they influenced the catalytic performances of HAP structure in OCM reactions. The selectivity to $\mathrm{C}_{2}$ (ethylene and ethane) products increased in the order of $\mathrm{HAP}-\mathrm{CO}_{3}<\mathrm{HAP}<\mathrm{Pb}-\mathrm{HAP}-\mathrm{CO}_{3}<\mathrm{Pb}-\mathrm{HAP}$, while $\mathrm{Pb}-\mathrm{HAP}-$ $\mathrm{CO}_{3}$ showed the best stability and comparable $\mathrm{C}_{2}$ yield (under optimized reaction conditions) to $\mathrm{Pb}-\mathrm{HAP}$ catalyst. Under different reaction temperature and/or $\mathrm{CH}_{4} / \mathrm{O}_{2}$ ratio in the OCM reactions, the $\mathrm{CH}_{4}$ conversion and $\mathrm{C}_{2}$ or $\mathrm{CO}_{\mathrm{x}}\left(\mathrm{CO}\right.$ and $\left.\mathrm{CO}_{2}\right)$ selectivity showed a strong dependence on the composition of HAP-based catalysts. The present study forms a basis for understanding of the correlations between the composition, structure, and catalytic performance of HAP and other apatite structured catalysts, which are potential membrane materials for OCM reactions in membrane reactors.

Keywords: Hydroxyapatite; membrane reactor; anion and cation substitution; methane; oxidative coupling. 


\section{Introduction}

The depletion of crude oil is shifting the market attention to natural gas that is still of great abundance $[1,2]$. Natural gas is made up of mainly methane $\left(\mathrm{CH}_{4}\right)$, which can substitute liquid petroleum for power generation and be a raw material in petrochemical industries. Rigorous research efforts have been made to convert methane into liquid fuels or chemicals. The most widely studied methane conversion processes include dry and steam reforming of methane to synthesis gas $\left(\mathrm{CO}+\mathrm{O}_{2}\right)$ followed by Fischer-Tropsch synthesis of higher hydrocarbons [3], non-oxidative direct methane conversion to aromatics $[4,5]$, and direct oxidative coupling of methane $(\mathrm{OCM})$ to $\mathrm{C}_{2}$ hydrocarbon $[6,7]$. In comparison with the first two processes, $\mathrm{OCM}$ is potentially more selective and economical given its unique capability in forming $\mathrm{C}_{2}\left(\mathrm{C}_{2} \mathrm{H}_{4}\right.$ and $\mathrm{C}_{2} \mathrm{H}_{6}$ ) hydrocarbons while circumventing the intermediate energy intensive steps in synthesis gas approach and fast catalyst deactivation by coke deposition in methane-to-aromatics approach. The more reactive nature of $\mathrm{C}_{2}$ products than methane in OCM reactions, however, leads to the sequential oxidation of $\mathrm{C}_{2}$ to $\mathrm{CO}_{\mathrm{x}}\left(\mathrm{CO}\right.$ or $\left.\mathrm{CO}_{2}\right)$. The attainable $\mathrm{C}_{2}$ yield in the OCM process is limited to $28 \%$ under a fixed-bed, continuous-feed reaction condition [8].

Membrane reactors comprised of active catalysts and $\mathrm{O}_{2}$ permeable membranes have potential to mitigate the limit on $\mathrm{C}_{2}$ yield in the OCM process [9]. The OCM reaction by catalytic membrane reactors involves both surface and gas-phase reactions. The $\mathrm{O}_{2}$ permeable membranes serve as $\mathrm{O}_{2}$ distributors to regulate gaseous $\mathrm{O}_{2}$ concentration in the reactor, which restricts the consecutive oxidation of $\mathrm{C}_{2}$ to $\mathrm{CO}_{\mathrm{x}}$. Although a substantial enhancement of the $\mathrm{C}_{2}$ yield has been predicted when an $\mathrm{O}_{2}$ permeable membrane was used in conjunction with an active OCM catalyst [10, 11], the parallel experimental studies on the OCM process in membrane reactors were not favorable due to lack of membranes with sufficient and harmonized 
catalytic and $\mathrm{O}_{2}$ permeable properties, and lack of rigorous description of the $\mathrm{O}_{2}$ kinetic effects on the OCM process in membrane reactors.

Hydroxyapatite $\left(\mathrm{Ca}_{10}\left(\mathrm{PO}_{4}\right)_{6}(\mathrm{OH})_{2}\right)$ is a type of calcium phosphate crystal more commonly studied in biomaterials because it is a major constituent of teeth and bones [12]. HAP has a hexagonal structure which is stable up to $1273 \mathrm{~K}$, and is comprised of $10 \mathrm{Ca}^{2+}$ ions located on two sets of non-equivalent sites, $4 \mathrm{Ca}_{[1]}$ on site 1 and $6 \mathrm{Ca}_{[2]}$ on site 2 in one unit cell [13]. The $\mathrm{Ca}_{[1]}$ is coordinated to 6 oxygen atoms belonging to different $\mathrm{PO}_{4}$ tetrahedra and also to 3 oxygen atoms at a larger distance. The $\mathrm{Ca}_{[2]}$ is found in cavities in the walls of the channels formed between the $\mathrm{Ca}$ and $\mathrm{O}$ atoms [14]. The $\mathrm{Ca}^{2+}$ cation and the anion, either $\mathrm{PO}_{4}{ }^{3-}$ in the $\mathrm{B}$ site or $\mathrm{OH}^{-}$in the A-site, can be substituted by other cation or anions using co-precipitation of a mixed cation and anion precursor solutions [15-17], sorption of cation solution onto HAP structure [18] as well as simple mixing of calcium hydroxide with a cation containing orthophosphoric acid solution [19]. These synthesis methods endow HAP with tunable thermal and chemical stability [20], catalytic properties [21, 22], and ion/electronic conductive properties [23]. $\mathrm{Pb}$ can substitute either $\mathrm{Ca}_{[1]}$ or $\mathrm{Ca}_{[2]}$, or both depending on the $\mathrm{Pb}$ concentrations in the structure, and $\mathrm{Pb}$-HAP were able to increase $\mathrm{C}_{2}$ selectivity by a factor of 5 compared to bare HAP [24]. Recent report on B-site substituted $\mathrm{HAP}-\mathrm{CO}_{3}$, in which the $\mathrm{PO}_{4}{ }^{3-}$ of $\mathrm{HAP}$ was partially substituted by $\mathrm{CO}_{3}{ }^{2-}$, showed that the oxide ion conduction was comparable to the yttria-stabilized-zirconia superionic conductor at $973 \mathrm{~K}$ [25]. Given the catalytic property of $\mathrm{Pb}$ HAP and oxide ion conductive property of $\mathrm{HAP}-\mathrm{CO}_{3}, \mathrm{~Pb}-\mathrm{HAP}-\mathrm{CO}_{3}$ is a promising apatite-based ceramic membrane material possessing $\mathrm{CH}_{4}$ activation and $\mathrm{O}_{2}$ permeation capabilities for efficient OCM reactions. Systematic investigation on both cation and anion substituted HAP in OCM reactions, however, is rarely accessible. 
In the present work, we report the synthesis of HAP catalysts with cation (Pb-HAP), anion $\left(\mathrm{HAP}-\mathrm{CO}_{3}\right)$, and both cation and anion $\left(\mathrm{Pb}-\mathrm{HAP}-\mathrm{CO}_{3}\right)$ substitutions. The effects of substitutions on physicochemical and acidity/basicity properties, and catalytic behaviors of HAPbased catalysts were assessed. X-ray diffraction (XRD), scanning electron microscopy (SEM), nitrogen adsorption, Fourier transform infrared (FTIR) and Raman spectroscopy, temperature programmed desorption of ammonia $\left(\mathrm{NH}_{3}-\mathrm{TPD}\right), \mathrm{X}$-ray photoelectron spectroscopy (XPS) and X-ray absorption fine structure spectroscopy (XAFS) were used to characterize the structural and physicochemical properties of the HAP-based catalysts. The catalytic behaviors of the HAPbased catalysts in OCM reactions were examined. It is shown that cation or anion substitution can change the composition and physicochemical properties of the HAP-based catalysts, and as consequences, the catalytic behaviors of HAP-based materials in OCM reactions.

\section{Experimental}

2.1 Materials. Ammoniun phosphate dibasic $\left(\left(\mathrm{NH}_{4}\right)_{2} \mathrm{HPO}_{4}, \geq 99.0 \%\right)$, ammonium chloride $\left(\mathrm{NH}_{4} \mathrm{Cl}, \geq 99.5 \%\right)$ and ammonia hydroxide solution $\left(\mathrm{NH}_{4} \mathrm{OH}, 28-30 \%\right)$ were supplied from Sigma-Aldrich. Lead nitrate $\left(\mathrm{Pb}\left(\mathrm{NO}_{3}\right)_{2}\right.$, A.C.S. Reagent) was purchased from J.T. Baker. Sodium bicarbonate $\left(\mathrm{NaHCO}_{3}, 99.7-100.3 \%\right)$ was provided by $\mathrm{BDH}$. Calcium nitrate tetrahydrate $\left(\mathrm{Ca}\left(\mathrm{NO}_{3}\right)_{2} \cdot 4 \mathrm{H}_{2} \mathrm{O},>99.5\right.$ purity) was purchased from Alfa-Aesar.

2.2 HAP-based catalysts preparation. The synthesis of bare HAP was carried out by first preparing a solution of $\left(\mathrm{NH}_{4}\right)_{2} \mathrm{HPO}_{4}(0.25 \mathrm{M}, 480 \mathrm{~mL})$ in one flask and a solution of $\mathrm{Ca}\left(\mathrm{NO}_{3}\right)_{2}$ $(0.37 \mathrm{M}, 320 \mathrm{~mL})$ in a second flask. After $\mathrm{pH}$ of each solution was raised to $\sim 10$ with $\mathrm{NH}_{4} \mathrm{OH}$, the two source solutions were mixed together by adding $\left(\mathrm{NH}_{4}\right)_{2} \mathrm{HPO}_{4}$ solution via a syringe pump (4 mL $\left.\min ^{-1}\right)$ to $\mathrm{Ca}\left(\mathrm{NO}_{3}\right)_{2}$ solution that was preheated to $363 \mathrm{~K}$ in an oil bath and was 
equipped with a reflux condenser. After addition of the $\left(\mathrm{NH}_{4}\right)_{2} \mathrm{HPO}_{4}$ solution, a milky white suspension was obtained and the suspension was kept at $363 \mathrm{~K}$ under magnetic stirring overnight followed by aging for 24 hours at room temperature. Finally, the product was collected by centrifugation at $6000 \mathrm{rpm}$ for $5 \mathrm{~min}$ and washed by dispersing in deionized (DI) water. The water washing and centrifugation steps were repeated 5 times. A vacuum oven was utilized to dry the wet product at $343 \mathrm{~K}$ overnight.

In the synthesis of $\mathrm{HAP}-\mathrm{CO}_{3}$ catalyst, the same procedure as that for HAP was employed except that a solution consisting of $\left(\mathrm{NH}_{4}\right)_{2} \mathrm{HPO}_{4}(0.25 \mathrm{M})$ and $\mathrm{NaHCO}_{3}(0.17 \mathrm{M})$ was prepared to replace $0.25 \mathrm{M}\left(\mathrm{NH}_{4}\right)_{2} \mathrm{HPO}_{4}$ solution in $\mathrm{HAP}$ synthesis. For synthesis of $\mathrm{Pb}-\mathrm{HAP}-\mathrm{CO}_{3}$ catalyst, the $\mathrm{Ca}\left(\mathrm{NO}_{3}\right)_{2}$ solution in the second flask was replaced with a solution of $\mathrm{Ca}\left(\mathrm{NO}_{3}\right)_{2}(0.4 \mathrm{M})$ and $\mathrm{Pb}\left(\mathrm{NO}_{3}\right)_{2}(0.1 \mathrm{M})$. The rest of procedure was the same as that for synthesis of $\mathrm{HAP}-\mathrm{CO}_{3}$ catalyst. The synthesis of Pb-HAP catalyst followed a reported procedure [16], which was similar to synthesis of bare HAP above except that an aqueous solution of $\mathrm{Pb}\left(\mathrm{NO}_{3}\right)_{2}(0.1 \mathrm{M}), \mathrm{Ca}\left(\mathrm{NO}_{3}\right)_{2}$ $(0.4 \mathrm{M})$ and $\mathrm{NH}_{4} \mathrm{Cl}(1.3 \mathrm{M})$ was prepared to replace $\mathrm{Ca}\left(\mathrm{NO}_{3}\right)_{2}(0.25 \mathrm{M})$ in HAP synthesis.

Finally, the vacuum dried HAP-based samples were calcined in flowing air $\left(150 \mathrm{~mL} \mathrm{~min}^{-}\right.$ ${ }^{1}$, ultrapure, Airgas) at $823 \mathrm{~K}$ for 5 hours at a ramp rate of $17.5 \mathrm{~K} \mathrm{~min}^{-1}$ from ambient temperature. All the samples were pelleted, crushed, and sieved to retain particle sizes between 180 and $425 \mu \mathrm{m}$ (40-80 mesh) for the following characterization and catalysis experiments.

2.3 Catalysts characterization. The morphologies of the HAP-based catalysts were observed by scanning electron microscopy (SEM) on a Hitachi SU-70 electron microscope. The crystallinity of the catalysts were examined by powder X-Ray diffraction (XRD) patterns using a Bruker D8 Advance Lynx Powder Diffractometer (LynxEye PSD detector, sealed tube, $\mathrm{Cu} K_{\alpha}$ radiation with $\mathrm{Ni} \beta$-filter). $\mathrm{N}_{2}$ adsorption-desorption isotherms of the samples were measured 
using an Autosorb-iQ analyzer (Quantachrome Instruments) at $77 \mathrm{~K}$. The specific surface areas of the samples were determined using (Brunauer, Emmett and Teller) (BET) method. Thermogravimetric analysis (TGA) of the catalyst samples was performed in a TGA instrument (2950, TA Instruments, Inc.) under a mixed air and $\mathrm{N}_{2}$ flow of $100 \mathrm{~mL} \mathrm{~min}^{-1}\left(40 \%\right.$ air, $60 \% \mathrm{~N}_{2}$ ) with a heating rate of $10 \mathrm{~K} \mathrm{~min}^{-1}$ from $308 \mathrm{~K}$ to $1273 \mathrm{~K}$. Elemental composition of the catalysts was determined by inductively coupled plasma optical emission spectroscopy (ICP-EOS, Optima 4300DV Instrument, Perkin-Elmer). The FTIR spectra of the samples were recorded with a spectrometer (Nicolet Magna-IR 560) in the range of $400-4000 \mathrm{~cm}^{-1}$. The Raman spectra of the catalysts were collected with a Raman spectrometer (LabRAM Aramis, Horiba Scientific) in the range of 200-2000 $\mathrm{cm}^{-1}$. XPS data was measured over a Kratos AXIS 165 spectrometer equipped with $165 \mathrm{~mm}$ radius hemispherical analyzer and eight channesltron detection system coupled with monochromatic Al radiation. The X-ray absorption fine structure spectroscopy (XAFS) measurements at the $\mathrm{Pb} \mathrm{L}_{3}$ edge $(\sim 13.036 \mathrm{keV})$ were conducted on the bending-magnet beamline of the Materials Research Collaborative Access Team (MRCAT) at the Advanced Photon source in Argonne National Laboratory. XAFS data were collected in the transmission mode under ambient condition. $\mathrm{PbO}, \mathrm{PbO}_{2}$ and $\mathrm{Pb}$ foil were considered as references and measured at the beamline. The $\mathrm{Pb}$ species fraction was calculated by conducting $\mathrm{Pb} \mathrm{X}$-ray absorption near edge spectroscopy (XANES) linear combination fittings using Athena in the IFEFFIT software package.

2.4 Determination of acidity of catalysts. The surface acidity of the HAP-based catalysts was evaluated by $\mathrm{NH}_{3}$-TPD using an Autosorb-iQ instrument (Quantachrome, ASIQM0000-4) equipped with a thermal conductivity detector (TCD). In the measurement, $0.1 \mathrm{~g}$ catalyst sample was loaded into a quartz reactor and heated at a rate of $10 \mathrm{~K} \mathrm{~min}^{-1}$ to $973 \mathrm{~K}$ under $\mathrm{He}(40 \mathrm{~mL}$ 
$\min ^{-1}$ ) and maintained at this temperature for 2 hours in order to remove the surface impurities. After being cooled to room temperature under He stream, the catalyst sample was exposed to $\mathrm{NH}_{3}$ (30 mL min ${ }^{-1}$, ultrapure, Airgas) stream for 0.5 hours. Physisorped $\mathrm{NH}_{3}$ was then removed by flowing He gas (30 mL min`1) for 2 hours. Afterwards, the catalyst sample was ramped to $1100 \mathrm{~K}$ at a ramp rate of $10 \mathrm{~K} \mathrm{~min}^{-1}$, and the $\mathrm{NH}_{3}$-TPD profile was recorded during this step.

2.5 OCM catalytic test. The catalytic reaction was performed in the reactor system that has been described in our previous work [26]. Typically, $0.3 \mathrm{~g}$ of catalyst sample was loaded in a U-shape tubular quartz reactor (10 $\mathrm{mm}$ inner diameter) which was placed inside a temperature controlled furnace (National Electric Furnace FA120 type). The temperature of the furnace was controlled by a Watlow Controller (96 series). A K-type thermocouple was attached to the outer wall of the reactor to monitor the temperature of the catalyst environment. The sample was pretreated in $\mathrm{He}$ and $\mathrm{O}_{2}$ atmosphere $\left(33 \mathrm{~mL} \mathrm{~min}^{-1}\right.$, volume ratio: $\left.91 \% \mathrm{He}, 9 \% \mathrm{O}_{2}\right)$ at $823 \mathrm{~K}$ for 4 hours prior to the OCM reactions. Afterwards, the catalyst was heated to the desired reaction temperature. The $\mathrm{CH}_{4}\left(8 \mathrm{~mL} \mathrm{~min}{ }^{-1}, 99.999 \%\right.$ purity, Airgas) and $\mathrm{O}_{2}\left(3 \mathrm{~mL} \mathrm{~min}{ }^{-1}, 99.9993 \%\right.$ purity, Airgas) diluted in $\mathrm{N}_{2}\left(5 \mathrm{~mL} \mathrm{~min}{ }^{-1}, 99.95 \%\right.$ purity, Airgas) and $\mathrm{He}\left(30 \mathrm{~mL} \mathrm{~min}^{-1}, 99.9993 \%\right.$ purity, Airgas) were sent via heated transfer lines hold at $343 \mathrm{~K}$ to the reactor. The reactant and product gases were analyzed using gas chromatograph (Agilent Technologies, 6890N) equipped with ShinCarbon ST packed column connected to a TCD. Dependency of $\mathrm{CH}_{4} / \mathrm{O}_{2}$ ratios was studied by changing the flow rates of $\mathrm{O}_{2}$ and the balance He gases while keeping constant flow rate in $\mathrm{CH}_{4}$. The blank test in the reactor without catalysts showed that the methane conversion was less than $1 \%$, suggesting that the gas phase reaction between $\mathrm{CH}_{4}$ and $\mathrm{O}_{2}$ was not favored under studied conditions. 


\section{Results and discussion}

3.1 Textural and structural properties of catalysts. Figure 1 shows the SEM images of the HAP-based catalysts. The bare HAP catalyst (Figure 1(A)) consists of uniform nanoparticles with sizes between $10 \mathrm{~nm}$ to $20 \mathrm{~nm}$. The particle sizes were determined by observing SEM images captured at multiple positions of the sample after loaded into SEM chamber. The nanoparticles tend to form irregular agglomerates. For $\mathrm{HAP}-\mathrm{CO}_{3}$ catalyst in Figure 1(B), capsule-like particles are observed. Upon Pb substitution into HAP (Pb-HAP), the sample turned into rod-shaped clusters, as shown in Figure 1(D). These rod-shaped clusters stacked on each other to form agglomerates. In the case of both cation and anion substituted $\mathrm{HAP}\left(\mathrm{Pb}-\mathrm{HAP}-\mathrm{CO}_{3}\right)$, a mixture of these morphologies were observed, as shown in Figure 1(C). The cation and anion,

Table 1. Chemical compositions and surface areas of HAP-based catalysts for OCM reactions.

\begin{tabular}{|c|c|c|c|c|c|c|c|}
\hline \multirow[t]{2}{*}{ Catalyst } & \multicolumn{3}{|c|}{ Composition $^{a}$} & \multicolumn{3}{|c|}{ Composition $^{b}$} & \multirow{2}{*}{$\begin{array}{c}\text { Surface } \\
\text { area }^{c} \\
\left(\mathrm{~m}^{2} / \mathrm{g}\right)\end{array}$} \\
\hline & $\mathrm{Pb} / \mathrm{Ca}$ & $\mathrm{C} / \mathrm{P}$ & $(\mathrm{Ca}+\mathrm{Pb}) /(\mathrm{P}+\mathrm{C})$ & $\mathrm{Pb} / \mathrm{Ca}$ & $\mathrm{C} / \mathrm{P}$ & $(\mathrm{Ca}+\mathrm{Pb}) /(\mathrm{P}+\mathrm{C})$ & \\
\hline $\mathrm{HAP}-\mathrm{CO}_{3}$ & 0.00 & 0.48 & 1.64 & 0.00 & 0.29 & 1.56 & 36 \\
\hline HAP & 0.00 & 0.00 & 1.65 & 0.00 & 0.00 & 1.59 & 39 \\
\hline $\mathrm{Pb}-\mathrm{HAP}-\mathrm{CO}_{3}$ & 0.17 & 0.44 & 1.73 & 0.33 & 0.34 & 1.64 & 37 \\
\hline Pb-HAP & 0.16 & 0.00 & 1.60 & 0.47 & 0.00 & 1.63 & 49 \\
\hline
\end{tabular}

${ }^{a}$ Determined by elemental analysis (ICP-OES). ${ }^{b}$ Determined from XPS measurement. ${ }^{c}$ Determined by BET method.

or both cation and anion substitutions did not dramatically change the particle sizes of HAP catalysts. The surface areas of the HAP-based catalysts were determined from $\mathrm{N}_{2}$ adsorptiondesorption isotherms and the results are listed in Table 1. Consistent with SEM results, there is no significant change in surface areas across these four HAP-based catalysts.

XRD, FTIR and Raman spectra were used to study crystal polymorphs of the HAP-based catalysts, and the results are shown in Figure 2(A)-(C). In Figure 2(A), all peaks of the XRD spectrum for $\mathrm{HAP}, \mathrm{HAP}-\mathrm{CO}_{3}, \mathrm{~Pb}-\mathrm{HAP}$ and $\mathrm{Pb}-\mathrm{HAP}-\mathrm{CO}_{3}$, respectively, are consistent with the 
crystalline HAP phase. This result indicates that HAP crystalline structure was well-preserved after the incorporation of cation $\left(\mathrm{Pb}^{2+}\right)$, anion $\left(\mathrm{CO}_{3}{ }^{2-}\right)$, or both cation and anion $\left(\mathrm{Pb}^{2+}\right.$ and $\left.\mathrm{CO}_{3}{ }^{2-}\right)$,
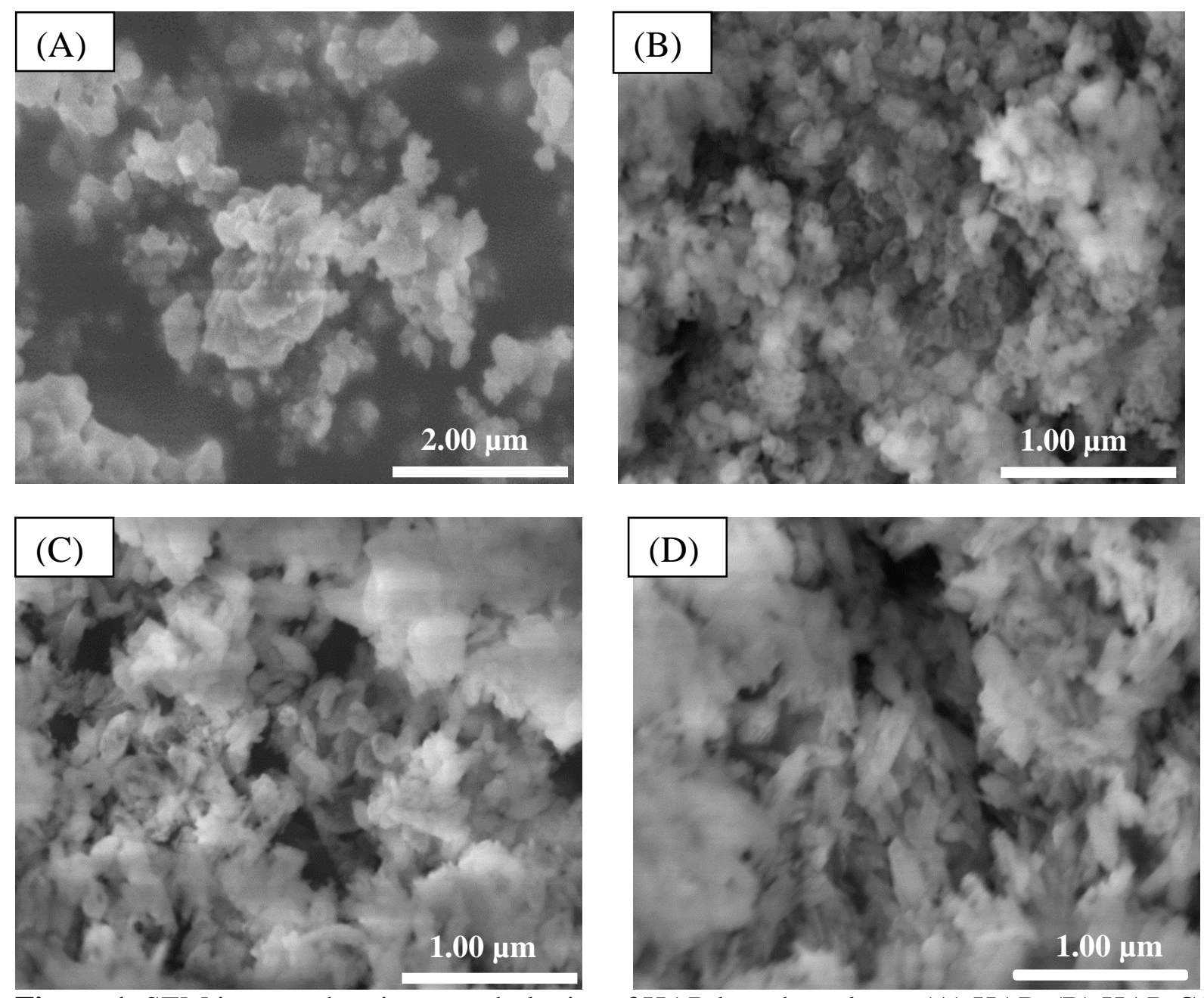

Figure 1. SEM images showing morphologies of HAP-based catalysts: (A) HAP, (B) HAP- $\mathrm{CO}_{3}$, (C) $\mathrm{Pb}-\mathrm{HAP}-\mathrm{CO}_{3}$, and (D) $\mathrm{Pb}-\mathrm{HAP}$, respectively.

respectively. A further examination on the XRD spectra shows that the peak position and width are slightly different across the HAP-based catalysts. Firstly, the diffraction peaks of $\mathrm{Pb}-\mathrm{HAP}$ and $\mathrm{Pb}-\mathrm{HAP}-\mathrm{CO}_{3}$ are shifted to lower diffraction angles compared to $\mathrm{HAP}$ and $\mathrm{HAP}-\mathrm{CO}_{3}$ samples. The left-shift of the diffraction peaks was caused by $\mathrm{Pb}^{2+}$ substitution, which has larger size than $\mathrm{Ca}^{2+}$ ions. It is reported that the incorporation of larger cations in the apatite materials expands the lattice parameters of the hexagonal structure and thus leads to an increase in unit cell volume, which in turns causes a downward shifting in $2 \theta$ diffraction angles [16]. Secondly, the 
diffraction peaks broaden from $\mathrm{HAP}$ to $\mathrm{HAP}-\mathrm{CO}_{3}$ and further to $\mathrm{Pb}-\mathrm{HAP}-\mathrm{CO}_{3}$ and $\mathrm{Pb}-\mathrm{HAP}$, suggesting that the crystallinity of HAP-based catalysts decreased with incorporation of cation, anion, or both type of ions into the crystalline HAP material. The broadening and left-shifting of the diffraction peaks in $\mathrm{Pb}-\mathrm{HAP}$ and $\mathrm{Pb}-\mathrm{HAP}-\mathrm{CO}_{3}$ samples might also be resulted from the presence of trivial amount of other crystalline phases such as hydroxypyromorphite (HPY). It is reported that HPY can be precipitated from the synthesis mixture similar to that of HAP used in the present study [27, 28]. The concurrent precipitation of HPY should be insignificant since no obvious diffraction peaks of HPY are observed in Figure 2(A).
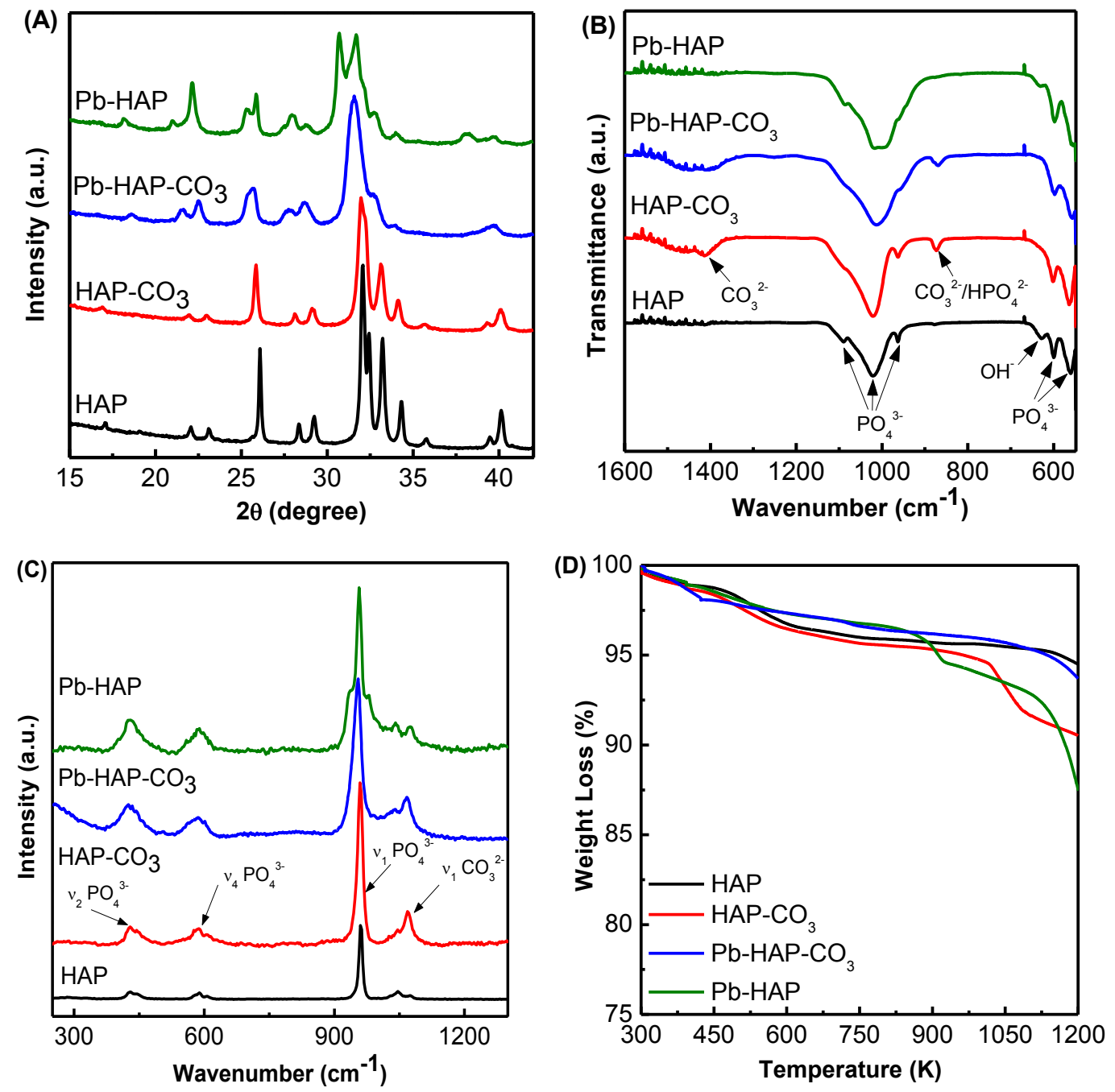

Figure 2. XRD patterns (A), FT-IR spectra (B), Raman spectra (C), and TGA curves (D) of HAP-based catalysts, respectively, used for OCM reactions. 
Figure 2(B) illustrates the FTIR spectra of HAP-based catalysts. The spectrum of bare HAP shows all absorption bands characteristic for HAP [29]. For $\mathrm{PO}_{4}{ }^{3-}$ group, the $v_{1}$ vibration (symmetric stretching) occurred at $942 \mathrm{~cm}^{-1}$, the $v_{3}$ vibration (asymmetric stretching) centered at $1000 \mathrm{~cm}^{-1}$ and $1100 \mathrm{~cm}^{-1}$, while $v_{1}$ vibration (asymmetric bending) located at $563 \mathrm{~cm}^{-1}, 600 \mathrm{~cm}^{-1}$, $942 \mathrm{~cm}^{-1}$, are all observed. The librational mode of $\mathrm{OH}^{-}$groups appears at $631 \mathrm{~cm}^{-1}$, suggesting the presence of hydroxyl groups in the bare HAP sample. Absence of any distinct bands in the range of $1400-1550 \mathrm{~cm}^{-1}$ indicates that bare HAP does not contain detectable carbonate $\left(\mathrm{CO}_{3}{ }^{2-}\right)$ groups. The vibrational modes of $\mathrm{PO}_{4}{ }^{3-}$ groups are also observed in $\mathrm{HAP}-\mathrm{CO}_{3}, \mathrm{~Pb}-\mathrm{HAP}-\mathrm{CO}_{3}$, and Pb-HAP samples (Figure 2(B)). This result suggests that the HAP structure was preserved upon cation, anion, or both substitutions, in agreement with the XRD results. The presence of broad vibrational bands centered at $1450 \mathrm{~cm}^{-1}\left(v_{3}\right.$ symmetric stretching of $\left.\mathrm{CO}_{3}{ }^{2-}\right)$, characteristic for substitution of $\mathrm{PO}_{4}{ }^{3-}$ by $\mathrm{CO}_{3}{ }^{2-}$ (B-type) [30, 31], in both $\mathrm{HAP}-\mathrm{CO}_{3}$ and $\mathrm{Pb}-\mathrm{HAP}-\mathrm{CO}_{3}$ samples indicates the incorporation of $\mathrm{CO}_{3}{ }^{2-}$ into the HAP structure. The absorption band at $631 \mathrm{~cm}^{-1}$ disappears in $\mathrm{HAP}-\mathrm{CO}_{3}$ and $\mathrm{Pb}-\mathrm{HAP}-\mathrm{CO}_{3}$, which resulted from the substitution of $\mathrm{OH}^{-}$by $\mathrm{CO}_{3}{ }^{2-}$ groups to form A-type substituted HAP. The FTIR spectra of $\mathrm{HAP}-\mathrm{CO}_{3}$ and $\mathrm{Pb}-\mathrm{HAP}-\mathrm{CO}_{3}$ overall suggest that AB-type $\mathrm{CO}_{3}{ }^{2-}$ substituted $\mathrm{HAP}$ was formed. The band at $872 \mathrm{~cm}^{-1}$ in the FTIR spectra of these two samples result from both $\mathrm{CO}_{3}{ }^{2-}\left(\mathrm{v}_{2}\right.$ in-plane bending of $\left.\mathrm{CO}_{3}{ }^{2-}\right)$ and $\mathrm{HPO}_{4}{ }^{2-}$ groups. It is reported that $\mathrm{HPO}_{4}{ }^{2-}$ groups are created to counterbalance the ionic charge when the $\mathrm{OH}^{-}$groups are replaced by $\mathrm{CO}_{3}{ }^{2-}$ in $\mathrm{HAP}$, which overlaps with the $\mathrm{CO}_{3}{ }^{2-}$ band at 872 $\mathrm{cm}^{-1}$. The absence of $\mathrm{CO}_{3}{ }^{2-}$ bands and appearance of $\mathrm{OH}^{-}$band at $631 \mathrm{~cm}^{-1}$ in Pb-HAP catalyst suggests no detectable $\mathrm{CO}_{3}{ }^{2-}$ groups in this sample. A slight shift of the vibration modes at 563 $\mathrm{cm}^{-1}$ and $600 \mathrm{~cm}^{-1}$ of $\mathrm{PO}_{4}{ }^{3-}$ groups toward lower wavenumbers in $\mathrm{Pb}-\mathrm{HAP}$ and $\mathrm{Pb}-\mathrm{HAP}-\mathrm{CO}_{3}$ reveals the presence of $\mathrm{Pb}^{2+}$ ions [32], consistent with left-shift of $2 \theta$ angles observed from XRD 
spectra. The features of FTIR spectra overall indicate that successful synthesis of cation $\left(\mathrm{Pb}^{2+}\right)$, anion $\left(\mathrm{CO}_{3}{ }^{2-}, \mathrm{AB}-\right.$ type $)$, and cation and anion $\left(\mathrm{Pb}^{2+}\right.$ and $\left.\mathrm{CO}_{3}{ }^{2-}\right)$ substituted $\mathrm{HAP}$ catalysts.

Raman spectra in Figure 2(C) are further used to understand the structural properties of the HAP-based catalysts. The vibration modes of $\mathrm{PO}_{4}{ }^{3-}$ groups in HAP structure, $v_{1}$ ( $\sim 960$ to 961 $\left.\mathrm{cm}^{-1}\right), v_{2}\left(\sim 430\right.$ to $\left.450 \mathrm{~cm}^{-1}\right), v_{3}\left(\sim 1035\right.$ to $1048 \mathrm{~cm}^{-1}$ and $\sim 1070$ to $\left.1075 \mathrm{~cm}^{-1}\right), v_{4}(\sim 587$ to 604 $\mathrm{cm}^{-1}$ ), confirm the apatite structure of all the catalysts [33]. The vibrational modes of the $\mathrm{CO}_{3}{ }^{2-}$ group are detected at $1073 \mathrm{~cm}^{-1}$ in $\mathrm{HAP}-\mathrm{CO}_{3}$ and $\mathrm{Pb}-\mathrm{HAP}-\mathrm{CO}_{3}\left(v_{1}\right.$ mode of B-type carbonate) [33], suggesting the presence of $\mathrm{CO}_{3}{ }^{2-}$ groups in these two samples, consistent with FTIR results above. The Raman peak at $960 \mathrm{~cm}^{-1}$ undergoes a shift to lower wavenumber $\left(928 \mathrm{~cm}^{-1}\right)$ when the bare HAP was substituted with $\mathrm{Pb}^{2+}$ ions, which is attributed to the stronger $\mathrm{Pb}-\mathrm{O}$ interactions compared with the Ca-O ones in HAP catalysts [24]. The absence of vibrational band at $~ 700$ $\mathrm{cm}^{-1}$ in Figure 2(C), which is assigned to an asymmetric $\mathrm{P}=\mathrm{O}$ stretching mode of $\mathrm{PO}_{4}{ }^{3-}$ groups in the stoichiometric HAP, indicates that all the as-synthesized HAP-based catalysts are nonstoichiometric [21, 34].

The thermal stability of the pre-calcined HAP-based catalysts was examined by TGA data presented in Figure 2(D). The TGA measurement was conducted on the as-synthesized HAP samples after the drying step in vacuum oven. The slight decrease in weight for all the samples at temperature from $300-750 \mathrm{~K}$ is assigned to the evaporation of water bound to the catalyst surface or decomposition of adsorbed ammonium or nitrate ions used in the catalyst synthesis. The weight loss at the temperature above $1100 \mathrm{~K}$ was caused by the structure decomposition such as dehydroxylation since the temperature approaches the thermal stability limit of the HAP material [35]. In the temperature range of 750-1100 K, these four HAP-based catalysts showed different thermal decomposition behaviors. The bare HAP is stable, but $\mathrm{HAP}-\mathrm{CO}_{3}$ has two weight losses. 
The first weight loss at $1030 \mathrm{~K}$ was due to the removal of $\mathrm{CO}_{3}{ }^{2-}$ groups from A-type substitution, while the second loss at $1100 \mathrm{~K}$ was resulted from the decomposition of B-type substituted $\mathrm{CO}_{3}{ }^{2-}$ groups [36]. Pb-HAP also has two weight losses in this temperature range. The first one at $830 \mathrm{~K}$ is assigned to the loss of chlorine component used in the catalyst preparation [21]. The second one at $1030 \mathrm{~K}$ can be attributed to the decomposition of HAP into a Pb-containing $\beta$-tricalcium phosphate. Compared to $\mathrm{Pb}-\mathrm{HAP}$ and $\mathrm{HAP}-\mathrm{CO}_{3}, \mathrm{~Pb}-\mathrm{HAP}-\mathrm{CO}_{3}$ has much better thermal stability in the temperature range of $750-1100 \mathrm{~K}$.

3.2 Composition analysis of HAP-based catalysts. The bulk and surface stoichiometry of the HAP-based catalysts were determined using ICP-OES and XPS analyses, respectively, and the results are listed in Table 1. The $\mathrm{Pb} / \mathrm{Ca}$ molar ratios in the synthesized samples are lower than the theoretical ratios $(\mathrm{Pb} / \mathrm{Ca}=0.25)$ used in catalyst synthesis. The cation/anion (i.e., $(\mathrm{Ca}+\mathrm{Pb}) /(\mathrm{P}+\mathrm{C}))$ molar ratios are slightly different, but close to the stoichiometric ratio of 1.67 . The substitution of $\mathrm{Pb}^{2+}$ cation or $\mathrm{CO}_{3}{ }^{2-}$ anion or both into the apatite structure did not alter the stoichiometry of HAP significantly. The surface element composition of the HAP-based catalysts in Table 1 shows that $\mathrm{Pb} / \mathrm{Ca}$ ratios and $(\mathrm{Ca}+\mathrm{Pb}) /(\mathrm{P}+\mathrm{C})$ ratios are higher and lower, respectively, than those determined from ICP-OES analysis for these four catalyst samples. This result suggests that $\mathrm{Pb}$ content is rich on the surface of the $\mathrm{Pb}-\mathrm{HAP}$ and $\mathrm{Pb}-\mathrm{HAP}-\mathrm{CO}_{3}$ samples.

The basicity/acidity of the HAP catalyst and thus their catalytic performance in OCM reactions are known to depend strongly on the chemical state of the cationic sites. XPS data was therefore measured to identify the chemical states of the cationic species $(\mathrm{Pb}$ and $\mathrm{Ca})$ in these post-calcined HAP-based catalysts. The presence of the desired elements $(\mathrm{Ca}, \mathrm{Pb}, \mathrm{P}$ and $\mathrm{O})$ 

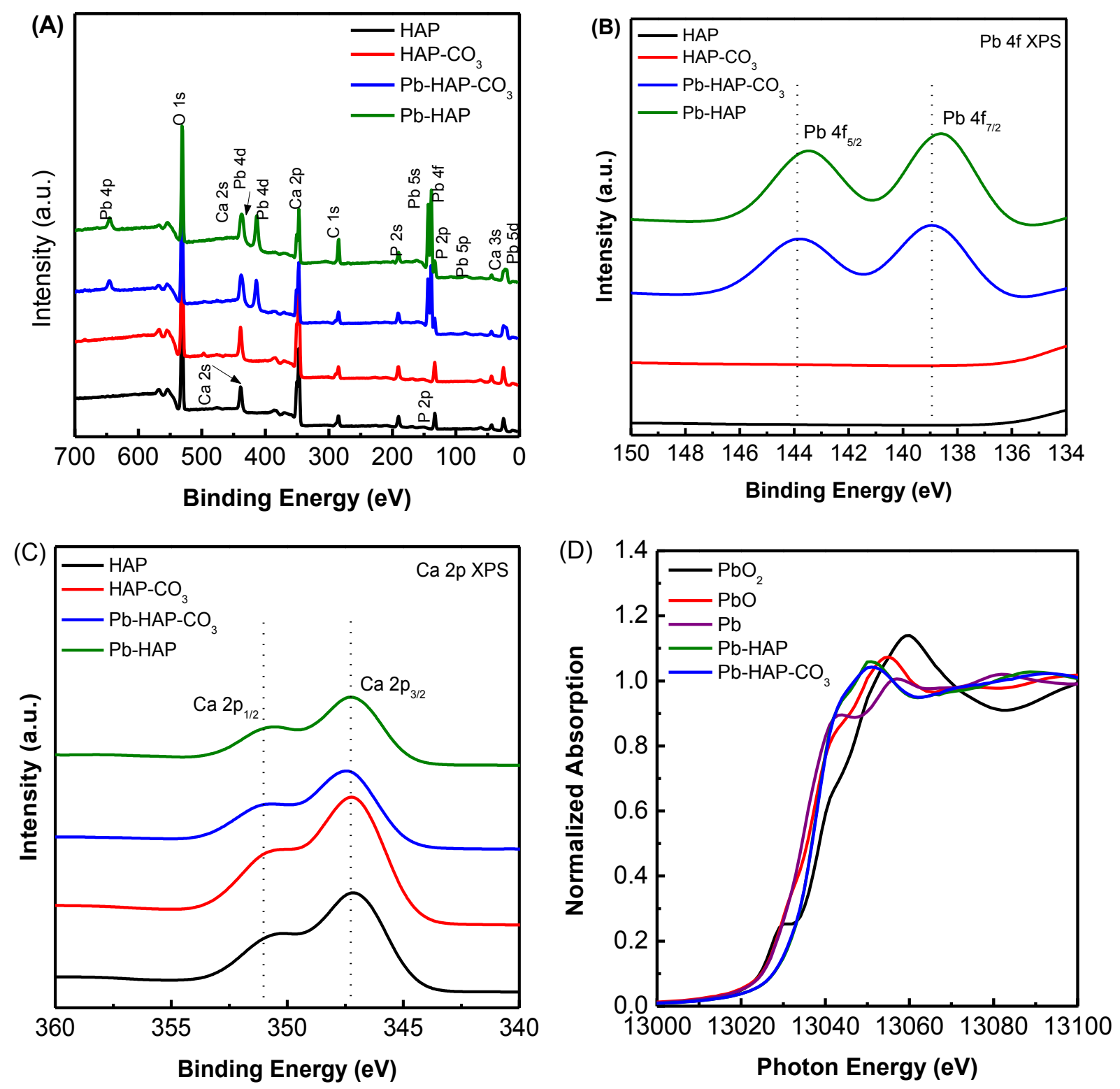

Figure 3. XPS spectra (A), $\mathrm{Pb} 4 \mathrm{f}$ spectra (B), Ca 2p (C) and XANES spectra (D) of HAP-based catalysts, respectively, used for OCM reactions.

in the final product (Figure 3(A)) indicates the successful preparation of the HAP-based catalysts. The binding energies of $\mathrm{Pb} 4 \mathrm{f}_{7 / 2}$ and $\mathrm{Pb} 4 \mathrm{f}_{5 / 2}$ of $\mathrm{Pb}-\mathrm{HAP}$ are lower than those of $\mathrm{Pb}-\mathrm{HAP}-\mathrm{CO}_{3}$ (Figure 3(B)), which suggests $\mathrm{Pb}^{2+}$ cations of $\mathrm{Pb}-\mathrm{HAP}$ were positioned in a more electronegative environment than those of $\mathrm{Pb}-\mathrm{HAP}-\mathrm{CO}_{3}$. There are two types of $\mathrm{Ca}$ sites in HAP materials: 9coordinated $\mathrm{Ca}_{[1]}$ and 7-coordinated $\mathrm{Ca}_{[2]}$. The basicity of an atom is well known to increase with 
increase in its coordination number $[37,38]$. It is expected that $\mathrm{Pb}^{2+}$ ions substitution for $\mathrm{Ca}_{[1]}$ would possess more basicity compared to $\mathrm{Ca}_{[2]}$, and thus, $\mathrm{Pb}$-HAP had more $\mathrm{Pb}^{2+}$ ions positioned at the $\mathrm{Ca}_{[1]}$ sites and higher basicity than $\mathrm{Pb}-\mathrm{HAP}-\mathrm{CO}_{3}$ catalyst. The binding energies of $\mathrm{Ca} 2 \mathrm{p}_{3 / 2}$ and $\mathrm{Ca} 2 \mathrm{p}_{1 / 2}$ in the HAP-based catalysts, however, are almost identical (Figure 3(C)). The XPS data suggests that the surface basicity of the catalyst is mainly related to the $\mathrm{Pb}^{2+}$ ions and their chemical states. The oxidation state and possible phases of $\mathrm{Pb}$ ions in $\mathrm{Pb}-\mathrm{HAP}$ and $\mathrm{Pb}-\mathrm{HAP}-\mathrm{CO}_{3}$ were studied using $\mathrm{Pb} \mathrm{L}_{3} \mathrm{XANES}$ spectra of $\mathrm{Pb}-\mathrm{HAP}$ and $\mathrm{Pb}-\mathrm{HAP}-\mathrm{CO}_{3}$. Figure 3(D) shows that both $\mathrm{Pb}-\mathrm{HAP}$ and $\mathrm{Pb}-\mathrm{HAP}-\mathrm{CO}_{3}$ exhibited similar adsorption energies at $13039 \mathrm{eV}$. The $\sim 3 \mathrm{eV}$ shift to higher energy than the metallic $\mathrm{Pb}$ foil indicates that $\mathrm{Pb}-\mathrm{HAP}$ is in higher oxidation state than zero. $\mathrm{Pb} \mathrm{L}_{3}$ edge represents mainly the $2 \mathrm{p} \rightarrow 6 \mathrm{p}$ transition for $\mathrm{Pb}^{2+}$-containing structures. On the other hand, a pre-edge at $\sim 13027 \mathrm{eV}$ representing $2 \mathrm{p} \rightarrow 6 \mathrm{~s}$ transition can be observed for $\mathrm{Pb}^{4+}$ ions (e.g., $\mathrm{PbO}_{2}$ ). The absence of pre-edge features in $\mathrm{Pb}-\mathrm{HAP}$ and $\mathrm{Pb}-\mathrm{HAP}-\mathrm{CO}_{3} \mathrm{XANES}$ spectra indicates that most $\mathrm{Pb}$ ions in the catalysts are in the $\mathrm{Pb}^{2+}$ state. There is no overlapping between $\mathrm{Pb}-\mathrm{HAP}$ and $\mathrm{PbO}$ reference, indicating that $\mathrm{Pb}^{2+}$ ions exist in the phase other than $\mathrm{PbO}$.

3.3 Surface acidity of HAP-based catalysts. The surface acidity and acid strength of the HAP-based catalysts were investigated using $\mathrm{NH}_{3}$-TPD. Phosphate groups in bare HAP are responsible for the acidity of the catalyst, whereas the $\mathrm{Ca}^{2+}$ ions are responsible for the basicity [36]. An increase in the basicity and acidity is expected upon $\mathrm{Pb}^{2+}$ and $\mathrm{CO}_{3}{ }^{2-}$ substitution into the HAP structure, respectively. Figure 4 shows $\mathrm{NH}_{3}$-desorption peaks exist in the regions of lower temperatures $(<600 \mathrm{~K})$, medium temperatures $(750-930 \mathrm{~K})$, and also at higher temperatures $(>$ $930 \mathrm{~K})$, respectively. This indicates the presence of weak, medium and strong acid sites in the HAP-based catalyst samples. The broad variation in peak intensity across these four HAP-based catalyst samples reveals that the catalysts differ from each other widely in their total number of 
acid sites and also in the strength of the acid sites. In the low temperature region in Figure 4, bare HAP exhibits a broad peak centered at $440 \mathrm{~K}$. This desorption peak is split into two peaks, one shifted downwards to $400 \mathrm{~K}$ and the other shifted upwards to $520 \mathrm{~K}$ in the sample of $\mathrm{HAP}-\mathrm{CO}_{3}$. When $\mathrm{Pb}^{2+}$ ions were incorporated into the $\mathrm{HAP}-\mathrm{CO}_{3}$ to form $\mathrm{Pb}-\mathrm{HAP}-\mathrm{CO}_{3}$, the acidity of the catalyst is significantly decreased, as reflected by the reduced intensity of the $\mathrm{NH}_{3}$-TPD peaks below $600 \mathrm{~K}$. Pb-HAP shows similar $\mathrm{NH}_{3}$-deosrpiton peak to that of $\mathrm{Pb}-\mathrm{HAP}-\mathrm{CO}_{3}$. The weak acidity in the catalysts follows the order of $\mathrm{HAP}-\mathrm{CO}_{3}>\mathrm{HAP}>\mathrm{Pb}-\mathrm{HAP} \sim \mathrm{Pb}-\mathrm{HAP}-\mathrm{CO}_{3}$. The medium acidity in these four catalysts shows the same trend to that of weak acidity. In the high temperature range $(750-930 \mathrm{~K}), \mathrm{HAP}-\mathrm{CO}_{3}$ and $\mathrm{HAP}$ have higher peak intensity than that of $\mathrm{Pb}$ $\mathrm{HAP}$ and $\mathrm{Pb}-\mathrm{HAP}-\mathrm{CO}_{3}$. The order of $\mathrm{NH}_{3}$-TPD peak intensity is $\mathrm{HAP}-\mathrm{CO}_{3}>\mathrm{Pb}-\mathrm{HAP}-\mathrm{CO}_{3}>$ $\mathrm{HAP}>\mathrm{Pb}-\mathrm{HAP}$.

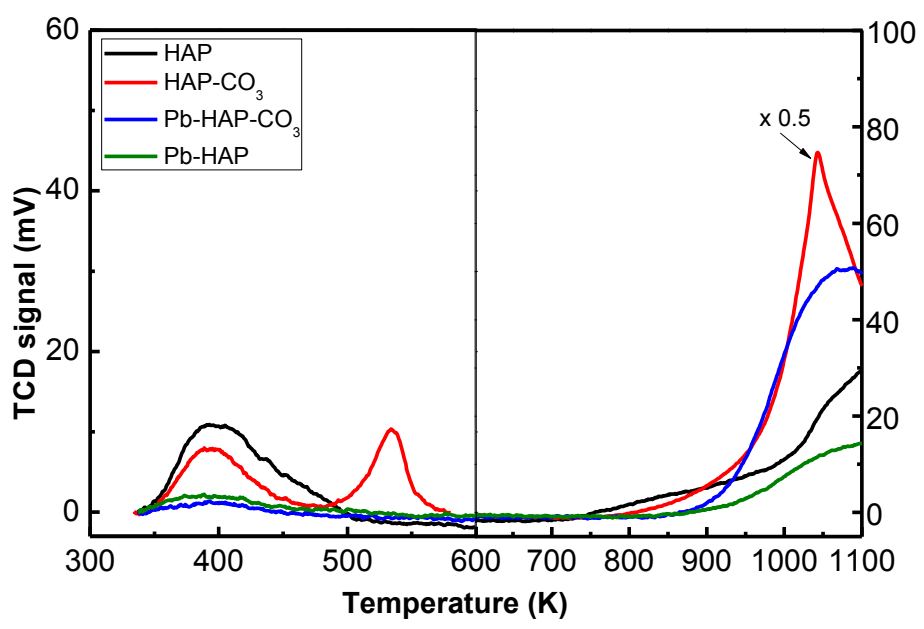

Figure 4. $\mathrm{NH}_{3}$-TPD Profiles of $\mathrm{HAP}, \mathrm{HAP}-\mathrm{CO}_{3}, \mathrm{~Pb}-\mathrm{HAP}$ and $\mathrm{Pb}-\mathrm{HAP}-\mathrm{CO}_{3}$ catalysts.

The libration of $\mathrm{NH}_{3}$ in the low temperature range in Figure 4 is mainly attributed to the $\mathrm{PO}_{4}{ }^{3-}$ groups present in the HAP catalysts [39]. The medium and high temperature $\mathrm{NH}_{3}$ desorption peaks are caused by the co-existed $\mathrm{PO}_{4}{ }^{3-}, \mathrm{CO}_{3}{ }^{2-}$ and $\mathrm{HPO}_{4}{ }^{2-}$ groups. The AB-type $\mathrm{CO}_{3}{ }^{2-}$ substituted HAP, as suggested by FTIR data, contains both $\mathrm{CO}_{3}{ }^{2-}$ groups in the A and $\mathrm{B}$ sites and $\mathrm{HPO}_{4}{ }^{2-}$ that is resulted from substitution of $\mathrm{OH}^{-}$groups by $\mathrm{CO}_{3}{ }^{2-[39]}$. The broad and 
strong high temperature desorption peak in $\mathrm{HAP}-\mathrm{CO}_{3}$ and $\mathrm{Pb}-\mathrm{HAP}-\mathrm{CO}_{3}$ might also be caused by the release of $\mathrm{CO}_{2}$ from $\mathrm{CO}_{3}{ }^{2-}$ groups in the apatite structure [40]. It is generally accepted that the strength and quantity of the acid sites are directly related to desorption temperature and intensity in $\mathrm{NH}_{3}$-TPD analysis. Therefore, the $\mathrm{NH}_{3}$-TPD data confirms that the acidity HAPbased catalysts was tuned upon $\mathrm{Pb}^{2+}, \mathrm{CO}_{3}{ }^{2-}$, or both substitutions. The absence of $\mathrm{CO}_{3}{ }^{2-}$ from $\mathrm{Pb}$ $\mathrm{HAP}-\mathrm{CO}_{3}$ catalyst further reduced the acidity of the catalyst since Pb-HAP only showed very weak $\mathrm{NH}_{3}$ desorption peaks. The reduction and enhancement in acidity upon $\mathrm{Pb}^{2+}$ and $\mathrm{CO}_{3}{ }^{2-}$ substitution, respectively, are consistent with composition and XPS analyses discussed above.

3.4 Performance of HAP-based catalysts in OCM reactions. The activity, stability and selectivity of the HAP-based catalysts in OCM reactions were firstly examined at $973 \mathrm{~K}$ and 101 $\mathrm{kPa}$ pressure. Figure 5(A) shows that the methane conversion followed a sequence of $\mathrm{Pb}-\mathrm{HAP}$ $\mathrm{CO}_{3}>\mathrm{HAP}>\mathrm{Pb}-\mathrm{HAP}>\mathrm{HAP}-\mathrm{CO}_{3}$. In addition, $\mathrm{HAP}$ and $\mathrm{Pb}-\mathrm{HAP}-\mathrm{CO}_{3}$ were more stable than $\mathrm{Pb}-\mathrm{HAP}$ and $\mathrm{HAP}-\mathrm{CO}_{3}$. The slight decrease in activity of $\mathrm{Pb}-\mathrm{HAP}$ with time on steam (TOS) and abrupt drop in activity of $\mathrm{HAP}-\mathrm{CO}_{3}$ in the beginning of the reaction was resulted from their structural instability, as shown by the TGA data in Figure 2(D). It should be noted that Pb-HAP$\mathrm{CO}_{3}$ maintained its activity and stability in the OCM reaction conditions. Figure 5(B) shows the product selectivity of the HAP-based catalysts with TOS of $6 \mathrm{~h}$ and methane conversion of $23 \%$. The $\mathrm{C}_{2}$ selectivity monotonically increases from $\mathrm{HAP}-\mathrm{CO}_{3}, \mathrm{HAP}, \mathrm{Pb}-\mathrm{HAP}-\mathrm{CO}_{3}$ to $\mathrm{Pb}-\mathrm{HAP}$ catalysts. The activity and selelctivity of these four HAP-based catalysts follows the reverse order of low and medium temperature desorption peak intensity in $\mathrm{NH}_{3}$-TPD profiles. $\mathrm{Pb}$ - $\mathrm{HAP}$ and $\mathrm{Pb}-\mathrm{HAP}-\mathrm{CO}_{3}$ are more active and selective in $\mathrm{C}_{2}$ formation. It is reported that $\mathrm{Pb}^{2+}$ ions form covalent bonds with carbon, which can stabilize methyl radicals and enable pairwise reaction of methyl radicals to form $\mathrm{C}_{2}$ products $[17,24,41-43]$. In $\mathrm{HAP}$ and $\mathrm{HAP}-\mathrm{CO}_{3}$ catalysts, the acidic 
environment promotes dissociative adsorption and builds up a strong interaction between the catalyst surfaces and $\mathrm{C}_{2}$ products. $\mathrm{C}_{2}$ products tend to stay on the surface of the catalyst which then undergoes secondary oxidation process to form $\mathrm{CO}$ and $\mathrm{CO}_{2}$ [44]. The trend of $\mathrm{C}_{2}$ selectivity across these catalysts is consistent with their surface composition and acidity changes. This result suggests that the tunable composition of the HAP-based catalysts by ion substitutions influences their physicochemical properties and consequently the selectivity in OCM reactions.
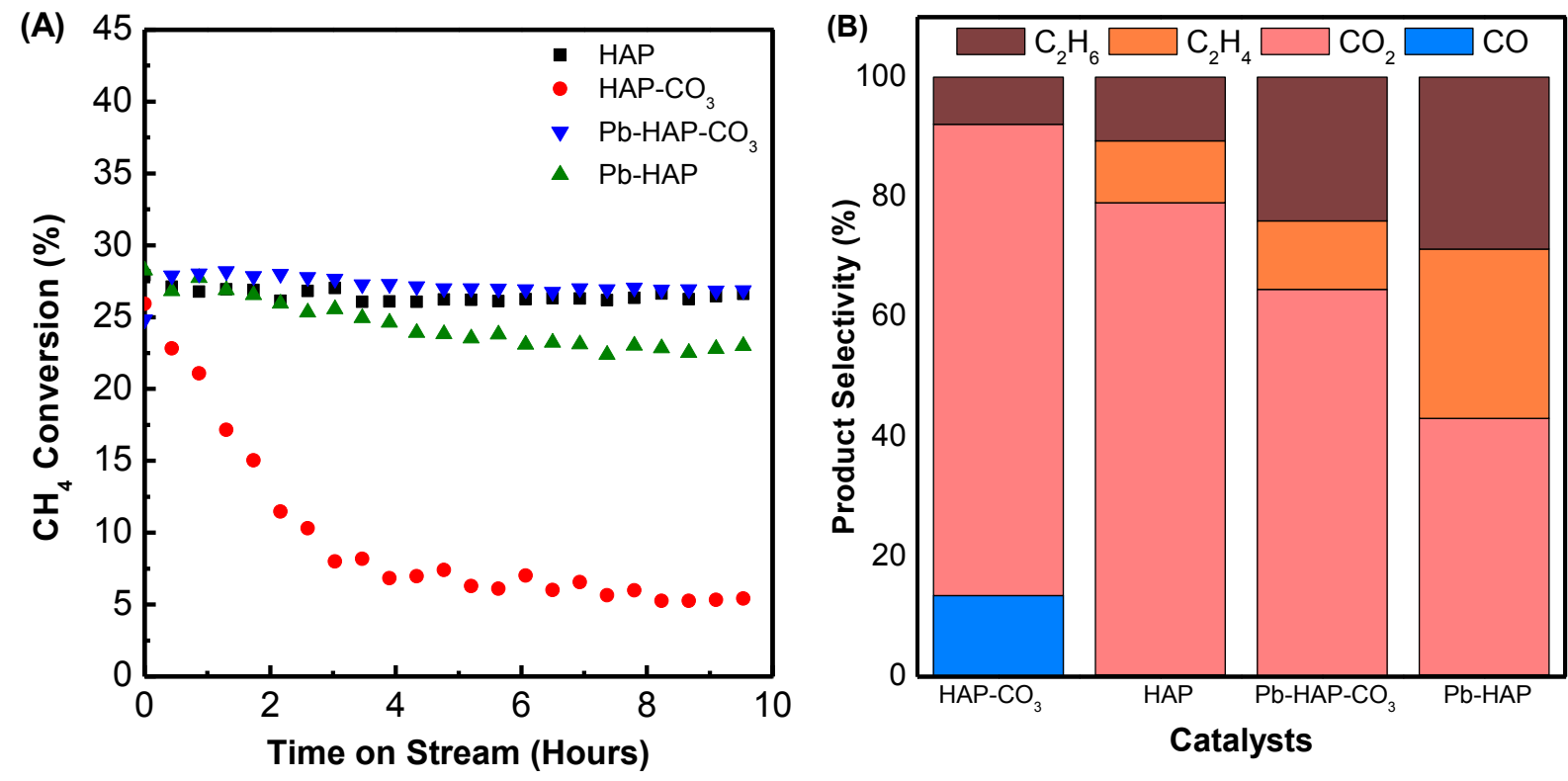

Figure 5. (A) Methane conversion with time-on-stream in OCM reactions and (B) Product selectivity for OCM reactions over HAP-based catalysts at $23 \%$ conversion under $973 \mathrm{~K}$ and 101 $\mathrm{kPa}$ pressure conditions and a space velocity of $8800 \mathrm{~mL} \mathrm{~g}_{\mathrm{cat}}{ }^{-1} \cdot \mathrm{hr}^{-1}$.

Methane conversion and product selectivity in OCM reactions over the HAP-based catalysts at different temperatures were studied. As shown in Figure 6(A), the methane conversion over $\mathrm{Pb}-\mathrm{HAP}$ and $\mathrm{Pb}-\mathrm{HAP}-\mathrm{CO}_{3}$ increased significantly with increasing temperature, while the conversion increased only slightly over $\mathrm{HAP}-\mathrm{CO}_{3}$ and $\mathrm{HAP}$ catalysts. This suggests that $\mathrm{Pb}$ species is the active component in the HAP-based catalyst for methane activation in OCM reactions, consistent with previous report [16]. Figure 6(B)-(D) shows the selectivity to 

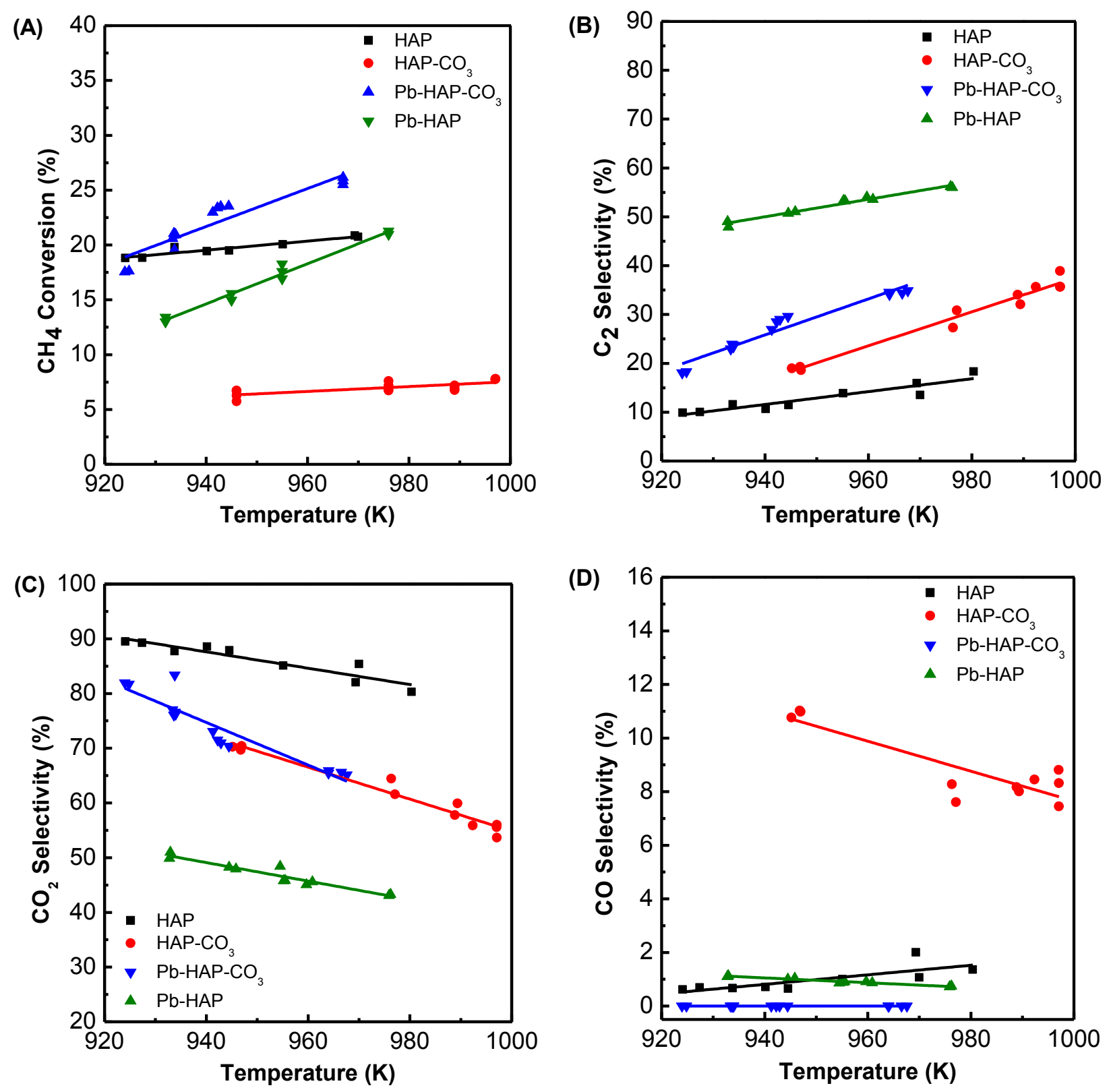

Figure 6. Methane conversion (A) and product selectivity $\left(\mathrm{C}_{2}(\mathrm{~B}) ; \mathrm{CO}_{2}(\mathrm{C}) ; \mathrm{CO}(\mathrm{D})\right)$ of $\mathrm{OCM}$ reactions over HAP-based catalysts at different temperatures. $\left(\mathrm{P}_{\mathrm{CH} 4}=27.1 \mathrm{kPa}, \mathrm{P}_{\mathrm{O} 2}=11.0 \mathrm{kPa}\right.$, total flow $=46 \mathrm{ml} \mathrm{min}^{-1}$, He was used as the balance gas).

$\mathrm{C}_{2}, \mathrm{CO}_{2}$, and $\mathrm{CO}$ products across these four catalysts at different reaction temperatures. $\mathrm{C}_{2}$ production was favored with increasing temperature, $\mathrm{CO}_{2}$ formation was inhibited, while $\mathrm{CO}$ formation was kept almost constant. It should be noted that $\mathrm{HAP}-\mathrm{CO}_{3}$ generated more $\mathrm{CO}$ than other HAP-based catalysts (Figure 5(B) and 6(D)). The methane reforming or reverse water gas 
shift reactions, caused by the acidity of $\mathrm{HAP}-\mathrm{CO}_{3}$ catalyst, can potentially contribute to the $\mathrm{CO}$ product.
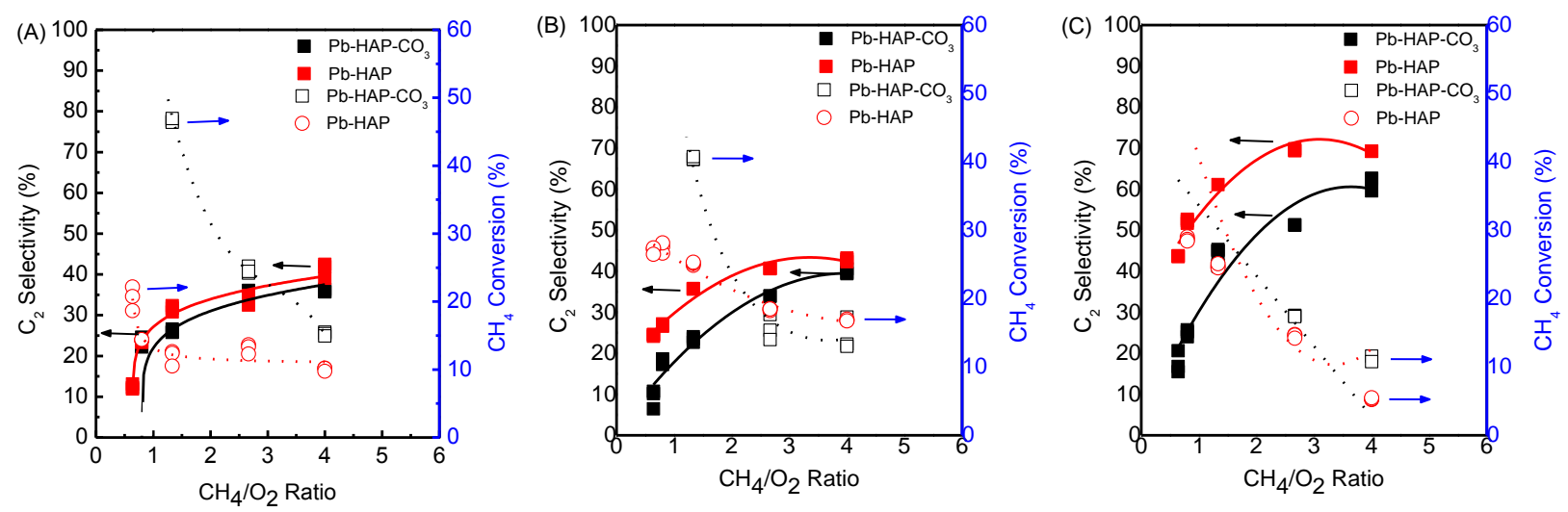

Figure 7. Effect of methane-to-oxygen $\left(\mathrm{CH}_{4} / \mathrm{O}_{2}\right)$ ratio on $\mathrm{C}_{2}$ selectivity and $\mathrm{CH}_{4}$ conversion at (A) $923 \mathrm{~K}$, (B) $943 \mathrm{~K}$ and (C) $973 \mathrm{~K}$ at a constant $\mathrm{CH}_{4}$ partial pressure of $25 \mathrm{kPa}$. (Total flow rate $\left.=46 \mathrm{~mL} \mathrm{~min}^{-1}\right)\left(\right.$ Filled symbol represents $\mathrm{C}_{2}$ selectivity, unfilled symbol represents $\mathrm{CH}_{4}$ conversion)

The effects of methane to oxygen ratio in OCM reactions was studied on the selected $\mathrm{Pb}$ $\mathrm{HAP}$ and $\mathrm{Pb}-\mathrm{HAP}-\mathrm{CO}_{3}$ catalysts at different temperatures. Figure 7 shows the methane to oxygen ratio is tuned by varying oxygen partial pressure (8.1/11.3/21.0/32.0/40.7 $\mathrm{kPa}$, respectively) while keeping a constant methane partial pressure of $25 \mathrm{kPa}$, and helium was used as the balance gas. $\mathrm{CH}_{4}$ conversion decreased with increasing $\mathrm{CH}_{4} / \mathrm{O}_{2}$ ratio while $\mathrm{C}_{2}$ selectivity increased with increasing $\mathrm{CH}_{4} / \mathrm{O}_{2}$ ratio at all the studied temperatures for both catalysts. Higher $\mathrm{CH}_{4} / \mathrm{O}_{2}$ ratio indicates lower $\mathrm{O}_{2}$ concentration in the gas phase in the reaction, which in turns promotes $\mathrm{C}_{2}$ formation since most of the $\mathrm{O}_{2}$ are activated on the surface of the catalyst. On the other hand, higher $\mathrm{CH}_{4} / \mathrm{O}_{2}$ ratio, i.e., lower $\mathrm{O}_{2}$ concentration, leads to lower $\mathrm{CH}_{4}$ conversion. Figures 7(A) also demonstrates that $\mathrm{CH}_{4}$ conversion over $\mathrm{Pb}-\mathrm{HAP}-\mathrm{CO}_{3}$ catalyst was higher than $\mathrm{Pb}-\mathrm{HAP}$ catalysts when the reaction temperature was low $(923 \mathrm{~K})$. With an increase in reaction temperature to $943 \mathrm{~K}$ (Figure 7(B)) or $973 \mathrm{~K}$ (Figure 7(C)), Pb-HAP and Pb-HAP-CO 3 showed similar methane conversion. The selectivity to $\mathrm{C}_{2}$ product, however, showed opposite trend with 
the reaction temperature. At the temperature of $923 \mathrm{~K}$ (Figure 7(A)), both catalysts have similar $\mathrm{C}_{2}$ selectivity in OCM reactions. With increasing reaction temperature to $943 \mathrm{~K}$ (Figure 7(B)), $\mathrm{Pb}-\mathrm{HAP}$ has higher $\mathrm{C}_{2}$ selectivity than that of $\mathrm{Pb}-\mathrm{HAP}-\mathrm{CO}_{3}$. The differences in $\mathrm{C}_{2}$ selectivity is more evident when the temperature was further increased to $973 \mathrm{~K}$ (Figure $7(\mathrm{C})$ ). With the available $\mathrm{C}_{2}$ selectivity and $\mathrm{CH}_{4}$ conversion data, the $\mathrm{C}_{2}$ yield, which is product of $\mathrm{C}_{2}$ selectivity and $\mathrm{CH}_{4}$ conversion, can be accessed. At lower reaction temperature $(923 \mathrm{~K}), \mathrm{Pb}-\mathrm{HAP}-\mathrm{CO}_{3}$ showed higher $\mathrm{C}_{2}$ yield than that of Pb-HAP catalyst. When the reaction temperature was increased to $973 \mathrm{~K}$, the $\mathrm{C}_{2}$ yield was higher in $\mathrm{Pb}-\mathrm{HAP}$ than $\mathrm{Pb}-\mathrm{HAP}-\mathrm{CO}_{3}$. These results suggest that the $\mathrm{C}_{2}$ production over $\mathrm{Pb}-\mathrm{HAP}-\mathrm{CO}_{3}$ can be optimized under certain reaction conditions. Overall, the OCM reaction data indicate that the catalytic performance of the HAP-based catalysts can be tuned upon cation or anion substations in the apatite structure. Given the catalyst stability, activity, selectivity and $\mathrm{O}_{2}$ permeable properties under optimized reaction condition, $\mathrm{Pb}-\mathrm{HAP}-\mathrm{CO}_{3}$ can be a potential catalyst to be integrated in membrane reactor to enable effective OCM reactions with side feeding of $\mathrm{O}_{2}$ through the membrane.

The crystallinity and structure of $\mathrm{Pb}-\mathrm{HAP}-\mathrm{CO}_{3}$ were studied after $\mathrm{OCM}$ reactions. Figure 8 shows the XRD, FTIR and Raman data, respectively, collected on $\mathrm{Pb}-\mathrm{HAP}-\mathrm{CO}_{3}$ sample after TOS of 10 hours. For comparison purpose, the XRD patterns of three other catalyst samples ( $\mathrm{HAP}, \mathrm{Pb}-\mathrm{HAP}$ and $\mathrm{Pb}-\mathrm{HAP}-\mathrm{CO}_{3}$ ) were measured and included in Figure 8(A). In comparison with Figure 2(A), the sharpness of the XRD peaks in all the samples was decreased, which indicates that crystallinity of the HAP-based catalyst might be reduced after OCM reaction. The $\mathrm{HAP}, \mathrm{Pb}-\mathrm{HAP}$ and $\mathrm{HAP}-\mathrm{CO}_{3}$ still maintain their initial diffraction peak positions. The $\mathrm{Pb}-\mathrm{HAP}-$ $\mathrm{CO}_{3}$, however, formed a new diffraction peak centered at $2 \theta \sim 30^{\circ}$. This diffraction peak can be indexed to the HPY structure. HPY has been reported to be synthesized from mixture of lead and 
phosphate precursor solutions $[27,28]$. In the OCM reaction condition, acidic environment of $\mathrm{Pb}-\mathrm{HAP}-\mathrm{CO}_{3}$ may facilitate the transformation of the HAP to HPY structure. It should be noted that the catalytic performance of $\mathrm{Pb}-\mathrm{HAP}-\mathrm{CO}_{3}$ did not decrease with time on stream of the $\mathrm{OCM}$ reaction (Figure 5). The FTIR (Figure 8(B)) spectra of $\mathrm{Pb}-\mathrm{HAP}-\mathrm{CO}_{3}$ sample after OCM reaction shows that the vibrational bands centered at $1450 \mathrm{~cm}^{-1}$, which corresponds to $v 3$ symmetric stretching of $\mathrm{CO}_{3}{ }^{2-}$. The band at $872 \mathrm{~cm}^{-1}$, which results from $\mathrm{CO}_{3}{ }^{2-}\left(\mathrm{v}_{2}\right.$ in-plane bending of $\mathrm{CO}_{3}{ }^{2-}$ ) group, can still be observed after 10 hours of reaction, implying that $\mathrm{CO}_{3}{ }^{2-}$ group was still present in the HAP structure. In the case of Raman spectra (Figure $8(\mathrm{C})$ ) of $\mathrm{Pb}-\mathrm{HAP}-\mathrm{CO}_{3}$, the vibrational modes of the $\mathrm{CO}_{3}{ }^{2-}$ group are detected at $1073 \mathrm{~cm}^{-1}$ after 10 hour of OCM reaction, again indicating that $\mathrm{Pb}-\mathrm{HAP}-\mathrm{CO}_{3}$ still maintained the carbonate group inside the structure.
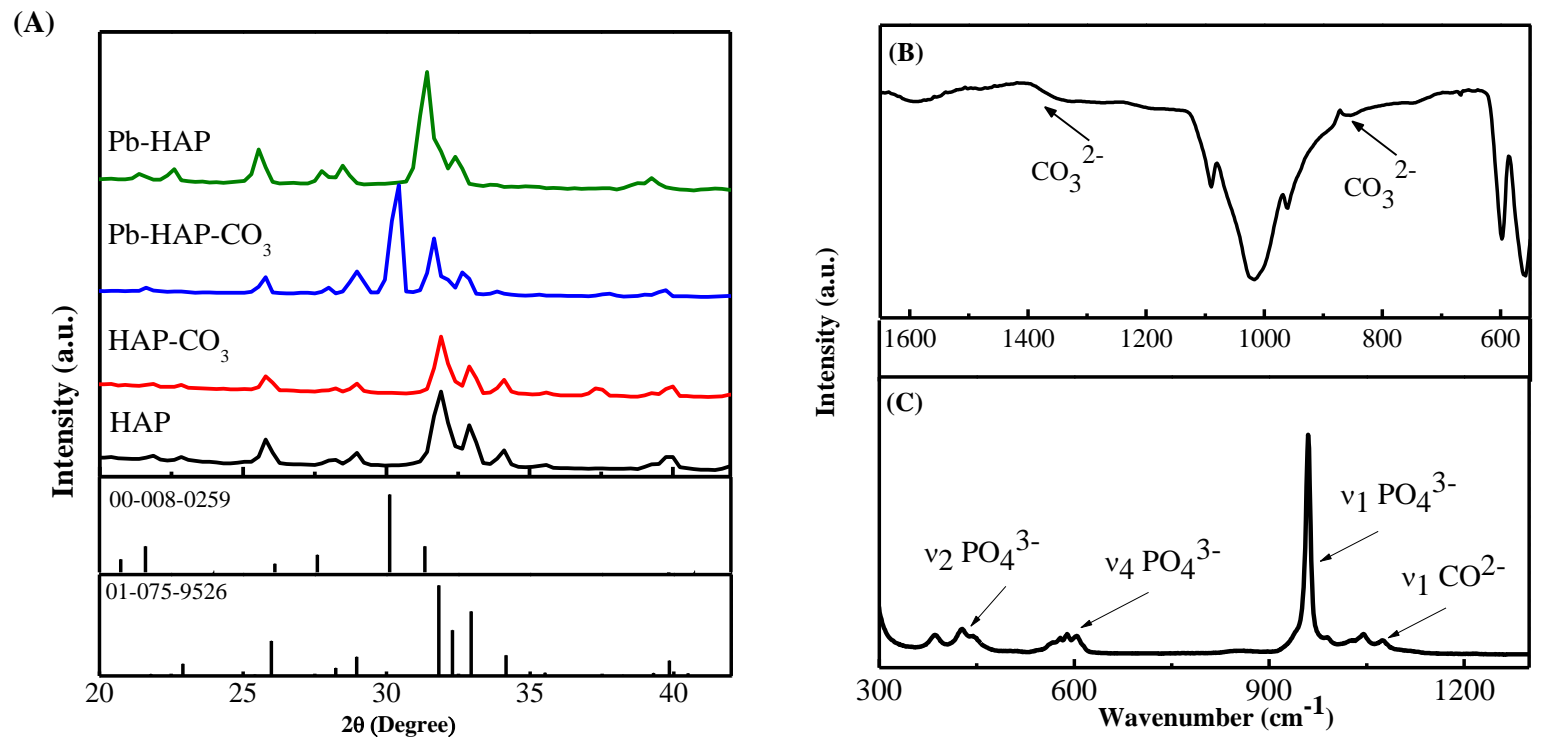

Figure 8. XRD pattern (A), FTIR (B) and (C) Raman of Pb-HAP-CO $\mathrm{CO}_{3}$ after 10-hour of OCM reaction. For comparison purpose, $\mathrm{XRD}$ patterns of $\mathrm{HAP}, \mathrm{HAP}-\mathrm{CO}_{3}$ and $\mathrm{Pb}-\mathrm{HAP}$ samples after 10 hour OCM reaction have also been presented in (A).

\section{Conclusions}


The HAP apatite structure with cation $\left(\mathrm{Pb}^{2+}\right)$, anion $\left(\mathrm{CO}_{3}{ }^{2-}\right)$, or both $\left(\mathrm{Pb}^{2+}\right.$ and $\left.\mathrm{CO}_{3}{ }^{2-}\right)$ substitutions have been synthesized. The physicochemical properties and catalytic behaviors of the HAP-based catalysts were assessed by a variety of characterizations and OCM catalysis tests. The $\mathrm{Pb}^{2+}$ and $\mathrm{CO}_{3}{ }^{2-}$ substitutions changed the composition and physicochemical properties of the HAP catalyst. The Pb-HAP- $\mathrm{CO}_{3}$ with both $\mathrm{Pb}^{2+}$ and $\mathrm{CO}_{3}{ }^{2-}$ substitutions exhibited the best thermal structural stability. The tunable composition of the HAP-based catalysts, and thus the tunable surface acidity environment, influences the catalytic behaviors of the catalysts in OCM reactions. The OCM catalysis studies showed that $\mathrm{C}_{2}$ selectivity increased with $\mathrm{Pb}^{2+}$ substitution in the catalysts whereas $\mathrm{Pb}-\mathrm{HAP}-\mathrm{CO}_{3}$ exhibited better stability in comparison with $\mathrm{Pb}-\mathrm{HAP}$. At the examined reaction temperatures of 923,943 , and $973 \mathrm{~K}$, the $\mathrm{CH}_{4}$ conversion and $\mathrm{C}_{2}$ selectivity decreased and increased, respectively, with increasing $\mathrm{CH}_{4} / \mathrm{O}_{2}$ ratios. The $\mathrm{C}_{2}$ yield showed a strong dependence on the composition of HAP-based catalysts and reaction conditions. The present work is for the first time a systematic examination of the effects of composition of HAP-based apatite materials on OCM reactions. The synthesis method, understating of the correlations between the composition, property, and catalytic performance of HAP-based catalysts are applicable to a range of apatite structured ceramic materials, which are potential membrane materials for OCM reaction in membrane reactors.

\section{Acknowledgements}

The authors gratefully acknowledge financial support from the ACS-Petroleum Research Fund (ACS-PRF) and National Science Foundation (NSF-CBET 1264599). We acknowledge the support of Maryland NanoCenter and its NispLab. The NispLab is supported in part by the NSF as a MRSEC Shared Experimental Facility. MRCAT operations are supported by the Department of Energy and the MRCAT member institutions. This research used resources of the Advanced 
Photon Source, a U.S. Department of Energy (DOE) Office of Science User Facility operated for the DOE Office of Science by Argonne National Laboratory under Contract No. DE-AC02$06 \mathrm{CH} 11357$.

\section{References}

[1] Holmen, A., Direct conversion of methane to fuels and chemicals, Catal Today 2009; 142: 28.

[2] Lunsford, J. H., Catalytic conversion of methane to more useful chemicals and fuels: a challenge for the 21st century, Catal Today 2000; 63: 165-174.

[3] Iglesia, E., Design, synthesis, and use of cobalt-based Fischer-Tropsch synthesis catalysts, Appl Catal A-Gen 1997; 161: 59-78.

[4] Guo, X., Fang, G., Li, G., Ma, H., Fan, H., Yu, L., Ma, C., Wu, X., Deng, D., Wei, M., Tan, D., Si, R., Zhang, S., Li, J., Sun, L., Tang, Z., Pan, X., Bao, X., Direct, Nonoxidative Conversion of Methane to Ethylene, Aromatics, and Hydrogen, Sci 2014; 344: 616-619.

[5] Zhang, J.-Z., Long, M. A., Howe, R. F., Molybdenum ZSM-5 zeolite catalysts for the conversion of methane to benzene, Catal Today 1998; 44: 293-300.

[6] Keller, G. E., Bhasin, M. M., Synthesis of ethylene via oxidative coupling of methane: I. Determination of active catalysts, J Catal 1982; 73: 9-19.

[7] Lunsford, J. H., The Catalytic Oxidative Coupling of Methane, Angew Chem Int Ed 1995; 34 : 970-980.

[8] Su, Y. S., Ying, J. Y., Green Jr, W. H., Upper bound on the yield for oxidative coupling of methane, J Catal 2003; 218: 321-333.

[9] Othman, N. H., Wu, Z., Li, K., A micro-structured La0.6Sr0.4Co0.2Fe0.8O3- $\delta$ hollow fibre membrane reactor for oxidative coupling of methane, J Membr Sci 2014; 468: 31-41.

[10] Coronas, J., Menéndez, M., Santamaria, J., Methane oxidative coupling using porous ceramic membrane reactors-II. Reaction studies, Chem Eng Sci 1994; 49: 2015-2025.

[11] Akin, F. T., Lin, Y. S., Oxidative coupling of methane in dense ceramic membrane reactor with high yields, AIChE Journal 2002; 48: 2298-2306.

[12] Suchanek, W., Yoshimura, M., Processing and properties of hydroxyapatite-based biomaterials for use as hard tissue replacement implants, J Mater Res 1998; 13: 94-117.

[13] Yamashita, K., Kitagaki, K., Umegaki, T., Thermal Instability and Proton Conductivity of Ceramic Hydroxyapatite at High Temperatures, J Am Ceram Soc 1995; 78: 1191-1197.

[14] Ellis, D. E., Terra, J., Warschkow, O., Jiang, M., Gonzalez, G. B., Okasinski, J. S., Bedzyk, M. J., Rossi, A. M., Eon, J.-G., A theoretical and experimental study of lead substitution in calcium hydroxyapatite, PCCP 2006; 8: 967-976.

[15] Marchat, D., Zymelka, M., Coelho, C., Gremillard, L., Joly-pottuz, L., Babonneau, F., Esnouf, C., Chevalier, J., Bernache-assollant, D., Accurate characterization of pure siliconsubstituted hydroxyapatite powders synthesized by a new precipitation route, Acta Biomater 2013; 9: 6992-7004.

[16] David, S., Serena, M. B., Production of zinc substituted hydroxyapatite using various precipitation routes, Biomed Mater 2013; 8: 025003. 
[17] Lee, K.-Y., Han, Y.-C., Suh, D. J., Park, T.-J., Pb-substituted Hydroxyapatite Catalysts Prepared by Coprecipitation Method for Oxidative Coupling of Methane, Stud Surf Sci Catal 1998; 119: 385-390.

[18] Tõnsuaadu, K., Gruselle, M., Villain, F., Thouvenot, R., Peld, M., Mikli, V., Traksmaa, R., Gredin, P., Carrier, X., Salles, L., A new glance at ruthenium sorption mechanism on hydroxy, carbonate, and fluor apatites: Analytical and structural studies, J Colloid Interface Sci 2006; 304: 283-291.

[19] Meirer, F., Pemmer, B., Pepponi, G., Zoeger, N., Wobrauschek, P., Sprio, S., Tampieri, A., Goettlicher, J., Steininger, R., Mangold, S., Roschger, P., Berzlanovich, A., Hofstaetter, J. G., Streli, C., Assessment of chemical species of lead accumulated in tidemarks of human articular cartilage by X-ray absorption near-edge structure analysis, J Synchrotron Radiat 2011; 18: 238244.

[20] Mostafa, N. Y., Characterization, thermal stability and sintering of hydroxyapatite powders prepared by different routes, Mater Chem Physics 2005; 94: 333-341.

[21] Park, J. H., Lee, D.-W., Im, S.-W., Lee, Y. H., Suh, D.-J., Jun, K.-W., Lee, K.-Y., Oxidative coupling of methane using non-stoichiometric lead hydroxyapatite catalyst mixtures, Fuel 2012; 94: 433-439.

[22] Gruselle, M., Apatites: A new family of catalysts in organic synthesis, J Organomet Chem 2015; 793: 93-101.

[23] Bouhaouss, A., Laghzizil, A., Bensaoud, A., Ferhat, M., Lorent, G., Livage, J., Mechanism of ionic conduction in oxy and hydroxyapatite structures, Int J Inorg Mater 2001; 3: 743-747.

[24] Matsumura, Y., Moffat, J., Catalytic oxidative coupling of methane over hydroxyapatite modified with lead, Catal Lett 1993; 17: 197-204.

[25] Tanaka, Y., Kikuchi, M., Tanaka, K., Hashimoto, K., Hojo, J., Nakamura, M., Nagai, A., Sugiyama, T., Munakata, F., Yamashita, K., Fast Oxide Ion Conduction Due to Carbonate Substitution in Hydroxyapatite, J Am Ceram Soc 2010; 93: 3577-3579.

[26] Wu, Y., Emdadi, L., Wang, Z., Fan, W., Liu, D., Textural and catalytic properties of Mo loaded hierarchical meso-/microporous lamellar MFI and MWW zeolites for direct methane conversion, Appl Catal A-Gen 2014; 470: 344-354.

[27] Lower, S. K., Maurice, P. A., Traina, S. J., Carlson, E. H., Aqueous Pb sorption by hydroxylapatite: Applications of atomic force microscopy to dissolution, nucleation, and growth studies, Am Mineral 1998; 83: 147-158.

[28] Narasaraju, T. S. B., Singh, R. P., Rao, V. L. N., A new method of preparation of solid solutions of calcium and lead hydroxylapatites, J Inorg Nucl Chem 1972; 34: 2072-2074.

[29] Hongquan, Z., Yuhua, Y., Youfa, W., Shipu, L., Morphology and formation mechanism of hydroxyapatite whiskers from moderately acid solution, Mater Res 2003; 6: 111-115.

[30] Gibson, I. R., Bonfield, W., Novel synthesis and characterization of an AB-type carbonatesubstituted hydroxyapatite, J Biomed Mater Res 2002; 59: 697-708.

[31] Genge, M. J., Jones, A. P., Price, G. D., An infrared and Raman study of carbonate glasses: implications for the structure of carbonatite magmas, Geochim Cosmochim Acta 1995; 59: 927937.

[32] Hadrich, A., Lautié, A., Mhiri, T., Vibrational study and fluorescence bands in the FTRaman spectra of $\mathrm{Ca} 10-\mathrm{xPbx}(\mathrm{PO} 4) 6(\mathrm{OH}) 2$ compounds, Spectrochim Acta A-Mol Biomol Spectros 2001; 57: 1673-1681.

[33] Penel, G., Delfosse, C., Descamps, M., Leroy, G., Composition of bone and apatitic biomaterials as revealed by intravital Raman microspectroscopy, Bone 2005; 36: 893-901. 
[34] Smith, R., Rehman, I., Fourier transform Raman spectroscopic studies of human bone, Journal of Materials Science: Mater Med 1994; 5: 775-778.

[35] Liao, C.-J., Lin, F.-H., Chen, K.-S., Sun, J.-S., Thermal decomposition and reconstitution of hydroxyapatite in air atmosphere, Biomater 1999; 20: 1807-1813.

[36] Silvester, L., Lamonier, J.-F., Vannier, R.-N., Lamonier, C., Capron, M., Mamede, A.-S.,

Pourpoint, F., Gervasini, A., Dumeignil, F., Structural, textural and acid-base properties of carbonate-containing hydroxyapatites, J Mater Chem A 2014; 2: 11073-11090.

[37] Climent, M. J., Corma, A., Iborra, S., Epping, K., Velty, A., Increasing the basicity and catalytic activity of hydrotalcites by different synthesis procedures, J Catal 2004; 225: 316-326.

[38] Yamaguchi, K., Ebitani, K., Yoshida, T., Yoshida, H., Kaneda, K., Mg-Al Mixed Oxides as Highly Active Acid-Base Catalysts for Cycloaddition of Carbon Dioxide to Epoxides, J Am Chem Soc 1999; 121: 4526-4527.

[39] Diallo-Garcia, S., Osman, M. B., Krafft, J.-M., Casale, S., Thomas, C., Kubo, J., Costentin, G., Identification of Surface Basic Sites and Acid-Base Pairs of Hydroxyapatite, J Phys Chem C 2014; 118: 12744-12757.

[40] Yasukawa, A., Kandori, K., Ishikawa, T., TPD-TG-MS Study of Carbonate Calcium Hydroxyapatite Particles, Calcif Tissue Int 2003; 72: 243-250.

[41] Matsumura, Y., Sugiyama, S., Hayashi, H., Moffat, J. B., Lead-Calcium Hydroxyapatite: Cation Effects in the Oxidative Coupling of Methane, J Solid State Chem 1995; 114: 138-145.

[42] Matsumura, Y., Moffat, J. B., Sugiyama, S., Hayashi, H., Shigemoto, N., Saitoh, K., Selective oxidative coupling of methane catalysed over hydroxyapatite ion-exchanged with lead, J Chem Soc, Faraday Trans 1994; 90: 2133-2140.

[43] Kong, J. I., Jung, J. S., Choi, J. G., Lee, S. H., Catalytic activity of LiSbTe2 for oxidative coupling of methane, App Catal A-Gen 2000; 204: 241-250.

[44] Zaera, F., Key unanswered questions about the mechanism of olefin hydrogenation catalysis by transition-metal surfaces: a surface-science perspective, PCCP 2013; 15: 11988-12003. 


\section{Graphical abstract}
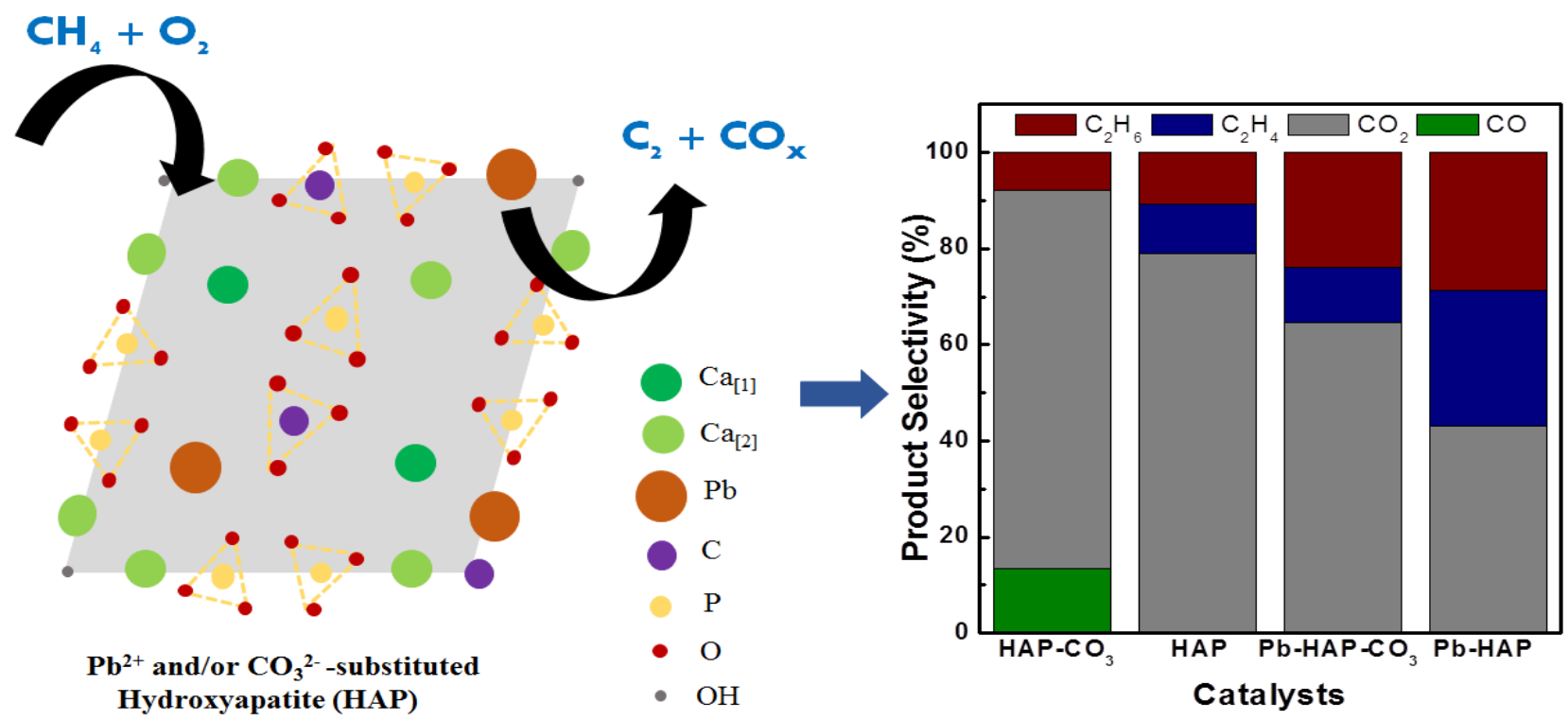